\title{
Correction to: 2020 CIS Annual Meeting: Immune Deficiency \& Dysregulation North American Conference
}

\author{
Tatiana Kalashnikova, $\mathrm{PhD}^{1} \cdot$ Nicola Wright, $\mathrm{MD}^{2}$ • Julian Midgley, $\mathrm{MD}^{3} \cdot$ Francois Bernier, $\mathrm{MD}^{4}$ • Joanne Luider, $\mathrm{MsC}^{5}$. \\ Luis Murguia-Favela, MD, FRCPC ${ }^{6}$
}

Published online: 11 July 2020

(C) Springer Science+Business Media, LLC, part of Springer Nature 2020

\section{Correction to: Journal of Clinical Immunology (2020) 40 (Suppl 1):S1-S163. https://doi.org/10.1007/s10875-020-00764-z}

The abstract with Submission ID\#809896 contained duplicate title and the main author was missing. The correct version is shown below:

\section{Immunodeficiency in patients with SGPL1 mutations}

Tatiana Kalashnikova ${ }^{1}$, Nicola Wright, $\mathrm{MD}^{2}$, Julian Midgley, $\mathrm{MD}^{3}$, Francois Bernier, $\mathrm{MD}^{4}$, Joanne Luider, $\mathrm{MsC}^{5}$, Luis Murguia-Favela, MD, FRCPC ${ }^{6}$

${ }^{1}$ Research Assistant/Section of Hematology and Immunology, Department of Pediatrics, Alberta Children's Hospital, Calgary, Canada

${ }^{2}$ Clinical Associate Professor, Hematologist/Section of Hematology and Immunology, Department of Pediatrics,
Alberta Children's Hospital, University of Calgary. Calgary, Canada

${ }^{3}$ Associate Professor/Section of Nephrology, Department of Pediatrics, Alberta Children's Hospital, University of Calgary, Calgary, Canada

${ }^{4}$ Head and Professor/Section of Medical Genetics, Department of Pediatrics, Alberta Children's Hospital, University of Calgary, Calgary, Canada

${ }^{5}$ Laboratory Scientist/Flow cytometry Lab, Calgary Laboratory Services, Calgary, Canada

${ }^{6}$ Pediatric Immunologist/Allergist, Department of Pediatrics, Alberta Children's Hospital, Calgary, Alberta, Canada

Publisher's Note Springer Nature remains neutral with regard to jurisdictional claims in published maps and institutional affiliations.
The online version of the original article can be found at https://doi.org/ 10.1007/s10875-020-00764-Z

Tatiana Kalashnikova, $\mathrm{PhD}$

tatianakalashnikova13@gmail.com

1 Research Assistant/Section of Hematology and Immunology, Department of Pediatrics, Alberta Children's Hospital, Calgary, Canada

2 Clinical Associate Professor, Hematologist/Section of Hematology and Immunology, Department of Pediatrics, Alberta Children's Hospital, University of Calgary, Calgary, Canada
3 Associate Professor/Section of Nephrology, Department of Pediatrics, Alberta Children's Hospital, University of Calgary, Calgary, Canada

4 Head and Professor/Section of Medical Genetics, Department of Pediatrics, Alberta Children's Hospital, University of Calgary, Calgary, Canada

5 Laboratory Scientist/Flow cytometry Lab, Calgary Laboratory Services, Calgary, Canada

6 Pediatric Immunologist/Allergist, Department of Pediatrics, Alberta Children's Hospital, Calgary, Alberta, Canada 